Skin

Appendage

Disorders
Skin Appendage Disord 2019;5:193-195

DOI: $10.1159 / 000493648$
Received: July 25, 2018

Accepted: September 10, 2018

Published online: November 16, 2018

\title{
Cicatricial Alopecia with Particular Trichoscopic and Histopathological Features
}

\author{
Helena Rocchetto Carolina Oliveira Costa Fechine Alessandra Anzai \\ Andreia Munck Adriana Rochetto Assalin Neusa Yurico Sakai Valente \\ Ricardo Romiti
}

Department of Dermatology, Hospital das Clínicas da Universidade de São Paulo, São Paulo, Brazil

\section{Question}

A 69-year-old woman presented with a 3-year history of hair and eyebrow loss. She complained of severe itching and admitted that she was constantly scratching her scalp. Physical examination revealed the absence of eyebrows and a frontal hairline recession, associated with thick skin in the frontoparietal area and short broken hairs (Fig. 1). Trichoscopic findings included the absence of vellus hairs and follicular openings, perifollicular scaling, as well as red and scaly scalp with broken hairs and with a shaft abnormality described as broom hair fibers. Histopathology showed hyperkeratosis, acanthosis, mild papillomatosis, perifollicular fibrosis, and mild lymphoplasmacytic infiltrate around the isthmus.

What is your diagnosis?

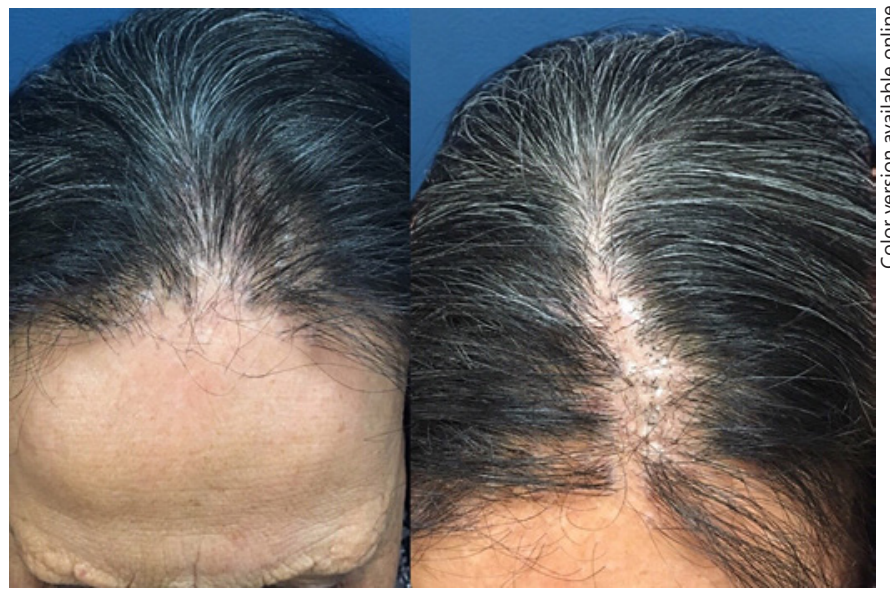

Fig. 1. Frontal hairline recession associated with thick skin in the frontoparietal area and short broken hairs. 


\section{Answer}

Association of Frontal Fibrosing Alopecia and Lichen Simplex Chronicus: Trichoscopy and Histopathological Features

Lichen simplex chronicus (LSC) is a recalcitrant skin disease characterized by lichenified patches, commonly located in the neck, ankles, scalp, and anogenital region [1-3]. It occurs as a result of constant scratching or rubbing of the skin and has been reported in the setting of other disorders such as atopic dermatitis, anxiety, or pruritus related to systemic disease $[1,2]$.

Trichoscopy of LSC, presenting with broom hair fibers, was first described in 2014 by Quaresma et al. [3]. Broom hairs are short hairs with a proximal breakage into two or three shafts and others with additional breakage at the distal tips into two or three shafts. These have also been reported in trichotillomania (TTM) [4], and, according to Quaresma et al. [3], the absence of other trichoscopic features of TTM and the presence of lichenification distinguishes these two disorders.
Histopathological features of LSC include hyperkeratosis, acanthosis with irregular elongation of the rete ridges, and papillomatosis (see Fig. 2b) [5]. Frontal fibrosing alopecia (FFA) is a primary lymphocytic scarring alopecia, characterized by progressive frontotemporal hairline recession [6]. Eyebrow loss occurs in the majority of patients and precedes scalp alopecia in 39\% [7].

Trichoscopic findings include the absence of follicular openings and vellus hair in the frontal hairline, follicular hyperkeratosis, perifollicular scaling, and erythema [8]. Histopathological features include inflammatory lymphocytic infiltration localized around the isthmus and concentric perifollicular fibrosis [9].

Since its first description, FFA has become an increasingly recognized and studied disease. The coexistence with other hair scalp diseases has already been reported, like androgenetic alopecia and lupus erythematosus [10]. Scalp pruritus was the most common presenting symptom in a clinical multicenter review, affecting $35 \%$ of the

Fig. 2. a Trichoscopic features. Broom hair fibers - short hairs with a proximal breakage into two or three shafts (right-facing arrows) and others with additional breakage at the distal tips into two or three shafts (left-facing arrows). b Histopathological features.

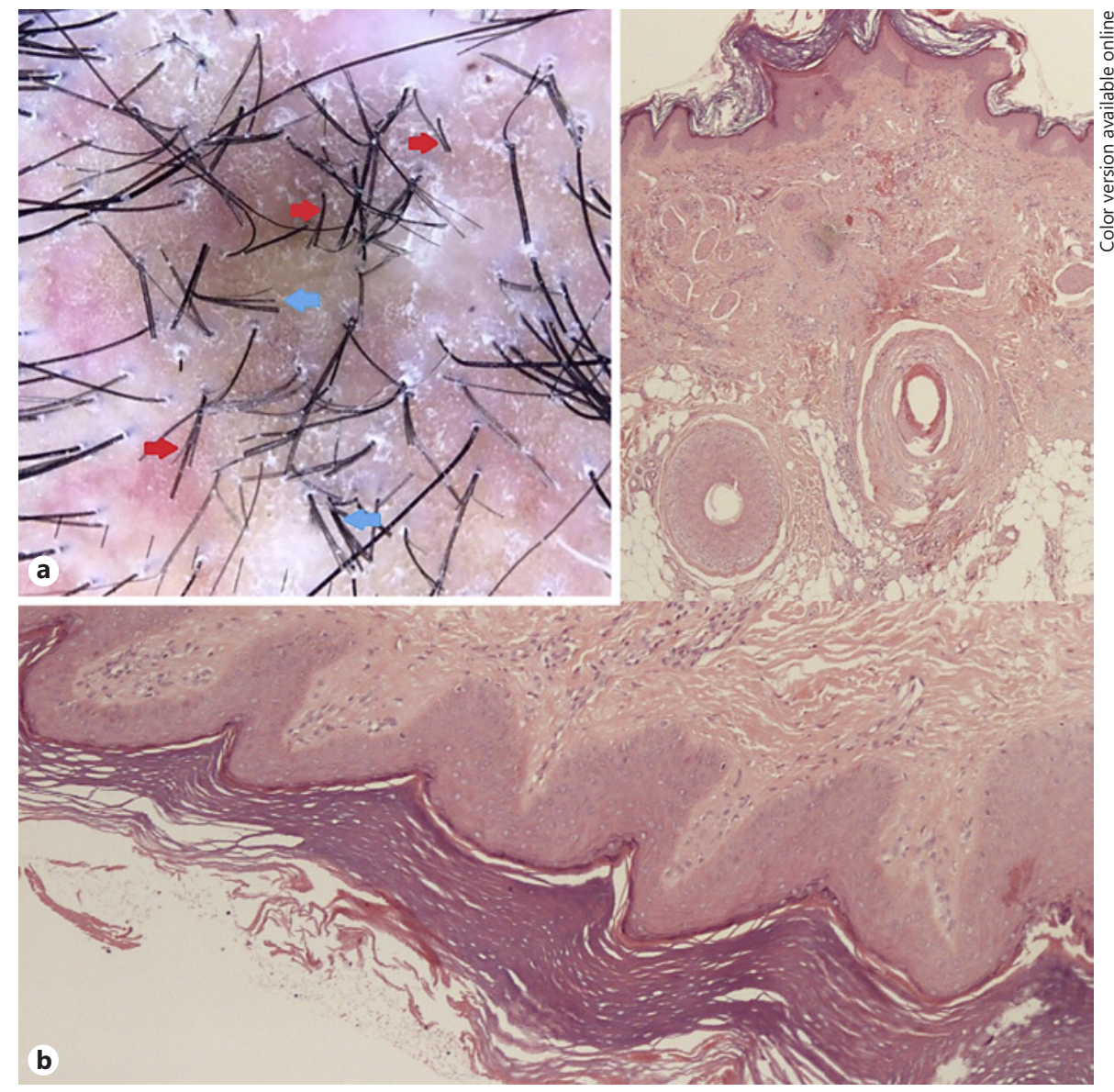


patients with FFA [7]. Our impression was that the development of LSC in areas affected by FFA may be related to pruritus of FFA.

In this case, trichoscopy showed features of FFA associated with a feature previously described in LSC - broom hair fibers $[3,8]$. As was the case in another report, the absence of other trichoscopic features of TTM and the presence of lichenification distinguishes LSC from TTM. Biopsies confirmed the diagnoses suggested by trichoscopy $[5,9]$.

Although both LSC and FFA are not uncommon, the association of both conditions has never been reported before. We report a patient who was diagnosed with both conditions, and we include our trichoscopic and histopathological findings.

\section{Statement of Ethics}

The patient's consent was obtained. The authors have no ethical conflicts to disclose.

\section{Disclosure Statement}

The authors have no conflicts of interest to disclose.

\section{Keywords}

Cicatricial alopecia $\cdot$ Frontal fibrosing alopecia $\cdot$ Lichen simplex chronicus - Trichoscopy

\section{References}

1 Roberston IM, Jordan JM, Whitlock FA. Emotions and skin (II)-the conditioning of scratch responses in cases of lichen simplex. Br J Dermatol. 1975 Apr;92(4):407-12.

2 Ambika H, Vinod CS, Sushmita J. A case of neurodermatitis circumscipta of scalp presenting as patchy alopecia. Int $J$ Trichology. 2013 Apr;5(2):94-6.

3 Quaresma MV, Mariño Alvarez AM, Miteva M. Dermatoscopic-pathologic correlation of lichen simplex chronicus on the scalp: 'broom fibres, gear wheels and hamburgers'. J Eur Acad Dermatol Venereol. 2016 Feb;30(2): $343-5$.
4 Rudnicka L, Rakowska A, Olszewska M, Slowinska M, Czuwara J, Rusek M, et al. Hair shafts. In: Rudnicka L, Olszewska M, Rakowska A, editors. Atlas of Trichoscopy Dermoscopy in Hair and Scalp Disease. London, UK: Springer; 2012. pp. 11-46.

5 Fernandez-Flores A. Lesions With an Epidermal Hyperplastic Pattern: Morphologic Clues in the Differential Diagnosis. Am J Dermatopathol. 2016 Jan;38(1):1-16.

6 Kossard S. Postmenopausal frontal fibrosing alopecia. Scarring alopecia in a pattern distribution. Arch Dermatol. 1994 Jun;130(6):7704.

7 Vañó-Galván S, Molina-Ruiz AM, SerranoFalcón C, Arias-Santiago S, Rodrigues-Barata AR, Garnacho-Saucedo G, et al. Frontal fibrosing alopecia: a multicenter review of 355 patients. J Am Acad Dermatol. 2014 Apr; 70(4):670-8.
8 Fernández-Crehuet $\mathrm{P}$, Rodrigues-Barata $\mathrm{AR}$, Vañó-Galván S, Serrano-Falcón C, MolinaRuiz AM, Arias-Santiago S, et al. Trichoscopic features of frontal fibrosing alopecia: results in 249 patients. J Am Acad Dermatol. 2015 Feb;72(2):357-9.

9 Tosti A, Piraccini BM, Iorizzo M, Misciali C. Frontal fibrosing alopecia in postmenopausal women. J Am Acad Dermatol. 2005 Jan;52(1): 55-60.

10 Gaffney DC, Sinclair RD, Yong-Gee S. Discoid lupus alopecia complicated by frontal fibrosing alopecia on a background of androgenetic alopecia. Br J Dermatol. 2013 Jul;169(1): 217-8. 